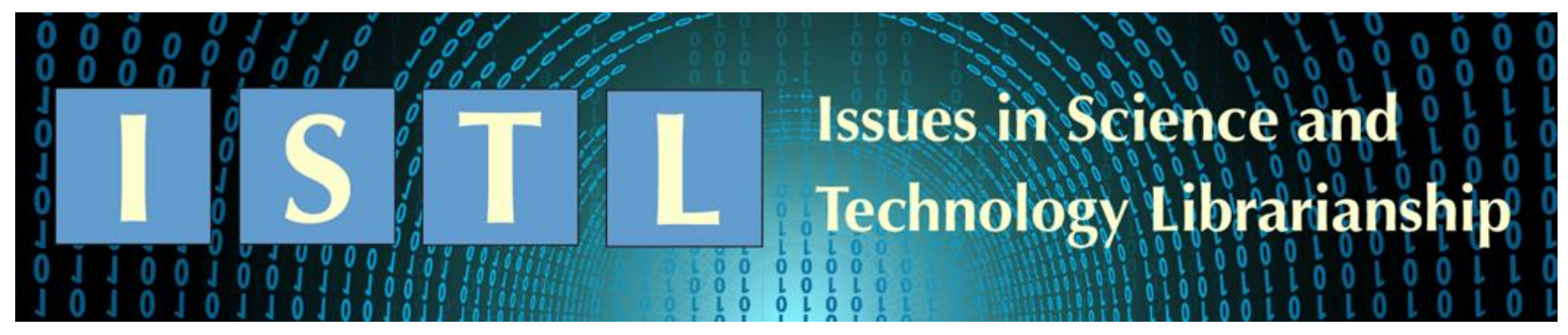

\title{
Research Support Services in STEM Libraries: A Scoping Review
}

\author{
Nedelina Tchangalova \\ Public Health Librarian \\ STEM Library \\ University of Maryland \\ College Park, MD \\ nedelina@umd.edu \\ Jodi Coalter \\ Life Sciences Librarian \\ STEM Library \\ University of Maryland \\ College Park, MD \\ jcoalter@umd.edu \\ Amy Trost \\ Data Services \& Business Librarian \\ Priddy Library \\ The Universities at Shady Grove \\ Rockville, MD \\ atrost1@umd.edu \\ Amber Pierdinock \\ Public Services Librarian \\ Library Learning Resource Center \\ Spartanburg Community College \\ Spartanburg, SC \\ pierdinocka@sccsc.edu
}

\begin{abstract}
As science and technology libraries continue to evolve, specialized research support services are developed and offered at academic institutions or research organizations. Making sense of this changing landscape and determining the best programs for an institution can be a daunting task, especially for early-career librarians. This article aims to provide an overview of various small to medium size non-traditional or specialized research support services in academic and special libraries serving Science, Technology, Engineering and Mathematics (STEM) disciplines. A systematic search of five databases was conducted for articles that described the development and implementation of research support services. Non-traditional or specialized research support services identified in this scoping review fall in the following areas: bibliometrics/altmetrics, data management services, geographic information systems, patents, and systematic reviews. The
\end{abstract}


paper provides a detailed foundation for novice and experienced STEM librarians to offer innovative library services or enhance existing research support services.

\section{Introduction}

For early-career Science, Technology, Engineering and Mathematics (STEM) librarians, the academic landscape is daunting to unravel (Hackenberg 2000; Beck \& Callison 2006; Garritano \& Carlson 2009; Tchangalova 2009). It is crucial for new STEM librarians to have a firm understanding of the various programs and services offered in academic and special libraries to ensure that they are establishing a career that is both productive and rewarding, as well as experienced librarians seeking to add value through additional programs and services.

Information overload is spreading in the scholarly community, and thus a need for synthesis of research evidence has been recognized by today's policymakers, managers, researchers, and practitioners. Collecting and analyzing primary studies to make important decisions is a timeconsuming process (Borah et al. 2017). For librarians, systematic and scoping reviews can be beneficial to identify strengths for various services they currently offer or plan to offer in the future. Scoping reviews typically involve a rigorous process of planning, identifying, selecting, and synthesizing the evidence based on a specific research question (Arksey \& O'Malley 2005). While the systematic reviews include a critical appraisal of the included studies, the scoping reviews aim "to map the literature on a particular topic or research area and provide an opportunity to identify key concepts; gaps in the research; and types and sources of evidence to inform practice, policymaking, and research" (Daudt et al. 2013).

This study aims to survey the various research support services to inform future programming in libraries serving STEM disciplines. The research team conducted a scoping review of the literature describing small to medium sized programs in research support services offered in special or academic STEM libraries, or libraries serving STEM departments or units. The included studies offer services that generally can be accomplished without multiple actors across departments, collaborations, and dependencies. While the included studies may seem large, either fiscally or departmentally, they are generally simpler in terms of scope for an early-career librarian to reasonably execute at least some of the components of the entire service suite.

\section{Definitions Used for this Study}

\section{STEM Disciplines}

Though commonly accepted as referring to science, technology, engineering, and mathematics, there are discrepancies amongst organizations as to which sciences are included in STEM definitions (Gonzalez \& Kuenzi 2012; U.S. Immigration and Customs Enforcement 2016). The National Science Foundation (NSF) has adopted a broad definition, including social sciences such as economics and politics within STEM, whereas the Department of Homeland Security and Immigration and Customs Enforcement (ICE) defined STEM as "engineering, biological sciences, mathematics, and physical sciences, or a related field." Related fields involve "research, innovation, or development of new technologies using engineering, mathematics, computer science or natural sciences." The authors of this scoping review used the narrower definition that excluded the social sciences and medicine, as these areas have been covered exhaustively by other scholars for inclusion in this scoping review (Mann \& Weightman 2013; Hardi \& Fowler 2014; Falconer 2015; Ludeman et al. 2015; Knehans et al. 2016; Roth 2018; Kung \& Chambers 2019). 


\section{STEM Library}

The American Library Association (date unknown) currently identifies four types of libraries: academic, public, school, and special libraries. This paper aims to identify research support services in academic and special libraries that offer unique opportunities to work with scientists and researchers in STEM disciplines. Smaller institutions and organizations usually have only one library supporting all disciplines, including STEM, while larger institutions may have several libraries on campus dedicated to serving particular disciplines or schools. For the purpose of this scoping review, articles and other sources are included regardless of the library size as long as it is serving faculty, students, staff, and researchers in STEM disciplines.

\section{Research Support}

The library profession has undergone many changes over the years, and librarians have transitioned from a focus on collections to service-oriented information professionals. Walter (2011) mentioned a "service turn" in libraries. The library is valued less for its physical collection and more for its scope and quantity of distinctive services, marked by a unique method of engagement or a connection with a campus' mission, identity, or history. These "distinctive services" will vary from library to library. But are there services that should be considered universal? What kinds of services would then be considered non-traditional or specialized?

Dempsey (2013) discussed a "shift to engagement" where the libraries begin to assess user's needs, anticipate changes in the user's environment/expectations, and build services to intersect those needs. Auckland (2012) outlined the many responsibilities of reference librarians, including systematic reviews, knowledge of databases, metadata creation, virtual networking advisory, data mining, measuring effect and quality of research, and data preservation. Goetsch (2008) described subject librarians as "renaissance librarians" who assist researchers with research consulting, information lifecycle management, networked and unique collection building, and information mediation and interpretation.

As users seek assistance at different stages of the research lifecycle, universities are moving toward hiring functional experts: librarians with high proficiency in areas such as geographic information systems (GIS), data management services, online learning, technology, programming, scholarly communication, and assessment (Jaguszewski \& Williams 2013). Other examples of research support include grant support, copyright consultations, digitization, assistance with data software, and digital scholarship (Johnson 2017; Chang et al. 2018; Cooper et al. 2019; Dohe et al. 2019).

This scoping review focuses on non-traditional or specialized research support services dedicated to supporting faculty, students and scientists engaged in research work. Since it takes some time for early-career librarians to build campus relationships and seek collaboration at a larger scale with greater impact to the larger organizational community, the findings are limited to small and medium scale services and programs that could be implemented with a small number of library colleagues or departmental faculty. More traditional services were excluded from the scoping review, such as interlibrary loan, information literacy instruction (e.g., one-shot instruction, competitions, orientations, scavenger hunts, speaker panels, etc.), embedded librarianship, makerspaces and other similar services as they are not considered specialized or non-traditional research support services. For example, much of the literature on makerspaces extends beyond the setting (academic or special libraries) laid out in this framework, as well as focuses on educational support rather than research support. Additionally, developing makerspaces are a large-scale endeavor for an academic or special library to develop and would not fall under the scope of a small to medium-sized library service. 


\section{Objectives}

The SPICE framework developed by Booth (2006) was used in the development of the research question: What are the small to medium size, non-traditional or specialized research support services in academic and special libraries serving STEM disciplines? (Figure 1).

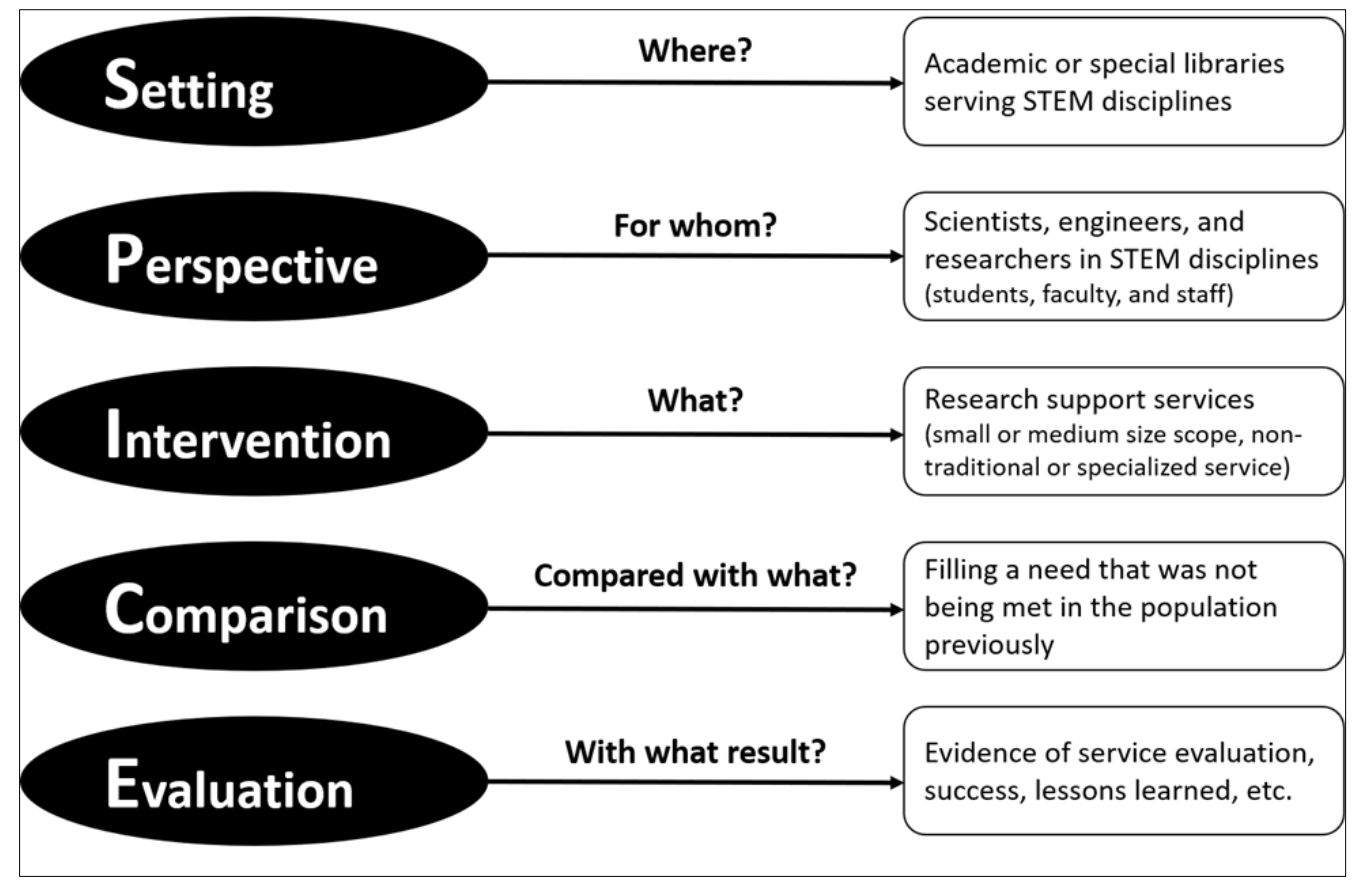

Figure 1. The SPICE framework used for this scoping review

\section{Methods}

The research team consisted of a librarian with training in systematic review techniques (NT), librarians with a science background (NT, JC), librarians with expertise in data visualization (JC, AT), and a library graduate student (AP). This study followed the Scoping Reviews (PRISMAScR) Checklist (Tricco et al. 2018), which is provided in Appendix 8.

\section{Identifying Search Terms}

Prior to conducting the scoping review, three approaches were used to identify keywords and combinations of terms to yield the most appropriate results: preliminary searches, visualization, and a survey. The first preliminary search was conducted in February 2019 across all EBSCO databases licensed by the University of Maryland (UMD) Libraries. Since the authors were collaborating with faculty on research projects, as well as offering research assistance regularly, the following truncated terms and phrases emerged and were used for this first round of preliminary search: "science-technology librar*" AND (collaborat* OR "research support" OR "research service*" OR "research consultation*" OR "research assistance"). A second preliminary search was also conducted across all EBSCO databases using the Science \& Technology Libraries subject field (DE=Descriptor) that was "exploded" to include other scitech library subject headings (Appendix 1). Searching EBSCO databases simultaneously using the Choose databases feature allowed the authors to identify the highest number of results and to decide on the number of databases to search for this scoping review (Appendix 1 and Appendix 2). Some emerging themes included research support through information literacy, building infrastructure for data management, exploring technology for research, etc. Related articles were scanned for keywords supplied by authors, subject terms, words in titles, and abstracts in the 
following areas: librarians collaborating with faculty in teaching students to conduct research (Salisbury \& Mattice 2016; MacDonald 2018); librarians managing big data (Antell et al. 2014; Johnson 2017); librarians propagating open science (Ogungbeni et al. 2018); librarians as partners in e-science (digital services) (Hunter et al. 2010); fostering collaborations with shared virtual reality technology (Smith \& Bridle 2018); and engagement through collections, instruction, and reference (Hubbard 2017).

Second, to capture all literature pertinent to the research topic, three librarians (JC, NT, AT) tested text mining and data visualization tools (Voyant, Systematic Review Accelerator, Tableau, Gephi, JSTOR Text Analyzer, and VOSviewer) to identify additional search terms in paper abstracts from the preliminary searches. They concluded that these tools required a cumbersome level of data cleanup and formatting producing very few additional search terms (Coalter et al. 2019). Print dictionaries and online thesauri were also consulted to identify related words, synonyms, and subject headings.

Finally, a survey with eight questions was developed (Appendix 3). The UMD Institutional Review Board (IRBNet ID\#1409490-1) approved the survey, and it was sent to nine STEMrelated listservs and discussion groups consisting of more than 5,443 subscribers (Appendix 4). Data were collected and managed using REDCap electronic data capture tools hosted at UMD (Harris et al. 2009; Harris et al. 2019). The goal was to reach out to other STEM librarians via email to discover new search terms based on libraries' names and job titles. Seventy-one librarians participated in the survey but none of them shared any studies, reports, books, or other grey literature that was relevant to this scoping review. However, six participants shared their job descriptions, four participants mentioned that they were offering a spectrum of data management services, one participant's library was currently exploring the development of a bibliometrics service, and two were providing a suite of research support services including grants and funding, digital scholarship, open research, publishing and copyright, text and data mining, and data visualization. The final list of search terms is presented in Appendix 5.

\section{Developing a Search Strategy}

One librarian (NT) created the search strategies (Appendix 6) and obtained expert advice for further improvement by email from a well-known Biomedical Information Specialist from the Netherlands (Wichor Bramer, e-mail message, April 11, 2019). Another UMD librarian with agricultural and natural sciences subject expertise provided feedback on the search terms (Stephanie Ritchie, personal communication with authors, April 16, 2019). After discussing the terms with other co-authors (JC, AP, AT) for inclusion as shown in Appendix 5, the search terms from the three main concepts, librarians/libraries, STEM, and research support, were combined with Boolean and proximity operators. Truncation was applied when necessary. The search strategy was checked for syntax and punctuation errors using a variety of tools, including the autocorrect feature in Microsoft Word and Grammarly, PRESS guidelines (McGowan et al. 2016), and BalanceBraces.com (Coalter et al. 2019). A single line search strategy was used for easier reproducibility and time efficiency (Bramer et al. 2018). The final search strategy was translated into the bibliographic databases of interest. Due to the large number of results obtained from the designed search strategy, one author (JC) used Google Books Ngram Viewer to inform when a particular term started to be a hot topic over the research span (Coalter et al. 2019). Although Google Books Ngram Viewer is designed to track the frequency of terms in Google books, the authors of this review found it valuable for tracking when a particular search term started to be heavily used in monographs. This technique provided additional insight on emerging topics in the literature. Based on this exploration, the results to scholarly literature were limited to those published between 1990 and 2020. 


\section{Study Selection}

Eligible articles included academic institutions and special libraries reporting on "unique" services (as defined) to STEM researchers involving areas such as infrastructure, services, and policy related to libraries. All types of articles reporting on research support services were considered, including qualitative and quantitative methods such as focus groups, interviews, statistical data, or anecdotal evidence. Articles describing health, medical, and hospital libraries were excluded because these publications were out of scope of this review. To develop the final set of inclusion criteria, the 4,242 records obtained from the preliminary searches as shown in Appendix 1 and Appendix 2 were imported into CADIMA, a free online tool that supports systematic review conduct and report. Two investigators (JC, AP) independently pilot tested the study selection on a random sample of records from the preliminary searches. They resolved the conflicts through discussion and consultation with a third member (NT). A list of inclusion and exclusion criteria are presented to assess the articles found during the preliminary searches and predetermined decisions (Table 1). There was no restriction on the geographical location, but results were limited to those published in English for the scoping review.

Table 1. Inclusion and exclusion criteria

\begin{tabular}{|c|c|c|}
\hline $\begin{array}{c}\text { SPICE } \\
\text { Framework }\end{array}$ & Inclusion Criteria & Exclusion Criteria \\
\hline Setting & $\begin{array}{l}\text { Academic or special libraries } \\
\text { serving STEM disciplines }\end{array}$ & $\begin{array}{l}\text { K-12 school libraries (media } \\
\text { libraries), public libraries, and } \\
\text { health, medical and hospital } \\
\text { libraries. }\end{array}$ \\
\hline Population & $\begin{array}{l}\text { Scientists, engineers, and } \\
\text { researchers (students, faculty, or } \\
\text { staff) in STEM disciplines }\end{array}$ & $\begin{array}{l}\text { Any researcher outside of the STEM } \\
\text { disciplines as defined (e.g., health, } \\
\text { medical or hospital) }\end{array}$ \\
\hline $\begin{array}{l}\text { Intervention/ } \\
\text { Exposure }\end{array}$ & $\begin{array}{l}\text { Small or medium size scope, } \\
\text { non-traditional or specialized } \\
\text { service (such as scholarly } \\
\text { communication, data } \\
\text { visualization, statistical } \\
\text { consulting, systematic review, } \\
\text { etc.) }\end{array}$ & $\begin{array}{l}\text { Traditional services such as } \\
\text { interlibrary loan, specialized library } \\
\text { instruction (e.g., R programming, } \\
\text { scholarly communication, standards, } \\
\text { etc.), makerspaces, course reserves, } \\
\text { institutional repositories, etc. }\end{array}$ \\
\hline Comparator & $\begin{array}{l}\text { Filling a need that was not } \\
\text { being met in the population } \\
\text { previously }\end{array}$ & N/A \\
\hline Evaluation & $\begin{array}{l}\text { Any evidence of service } \\
\text { evaluation, success, lessons } \\
\text { learned, potential for future } \\
\text { service development or benefits } \\
\text { for the library and its users. }\end{array}$ & N/A \\
\hline
\end{tabular}


The authors agreed on a selection of appropriate databases based on their preliminary searches and current UMD Libraries' subscriptions. On April 22, 2019, a search was performed in four EBSCO databases - Academic Search Ultimate, Education Source, Library \& Information Science Source, and MASTERFile, as well as in Web of Science. The results were imported into Zotero, a bibliographic management software, for deduplicating results across databases and screening the records. An updated search was executed on August 12, 2020 to identify more recent publications. The primary author (NT) independently applied inclusion/exclusion criteria to all title/abstract studies. If relevancy was difficult to ascertain from an abstract, the full text was consulted.

In addition, citation searching was performed in reference lists of literature reviews, systematic or scoping reviews discovered by the initial searches, as well as the reference lists of included studies. All authors also checked specific library journals for relevant research support services: Issues in Science and Technology Librarianship, Journal of eScience Librarianship, Journal of Map \& Geography Libraries, Reference and User Services Quarterly, and Science \& Technology Libraries. A manual search was also performed in the conference papers of the Engineering Libraries Division of the American Society for Engineering Education. The authors searched Google in incognito mode to minimize the effects of saving the browsing history, as well as using Google Advanced Search, including limiting document types (.pdf and .doc) and site domains (.edu, .org, .gov). Using a Google Scholar search methodology as described in two studies by Bramer et al. (2016, 2017), the authors of this paper reviewed the first 200 records from each search string developed for the five services identified in this review (Appendix 6). Through this supplementary searching, 17 articles were identified based on title and/or abstract.

\section{Data Abstraction and Analysis}

Once the studies that met the inclusion criteria were identified for inclusion in this review, the relevant data from each study was extracted. For each study, one investigator (NT) obtained the data in an Excel spreadsheet, while two members (JC, AT) checked for relevancy and accuracy. Extracted data included publication information, country of origin, library type, service type, and summaries, main outcomes, and program evaluations. The aim was to examine the size and scale of the implemented study to identify small and medium scale research support services that a STEM librarian could use to either enhance existing services or initiate and lead the development of new innovative ones.

\section{Results}

\section{Literature Search}

A PRISMA diagram displaying the number of results at various stages of this research process is presented in Figure 2. A total of 24,720 records were retrieved from database searches, and after removing duplicates, 19,873 records were screened by title and abstract. One hundred sixteen records were selected for full text review. Forty-five papers met the inclusion criteria. 


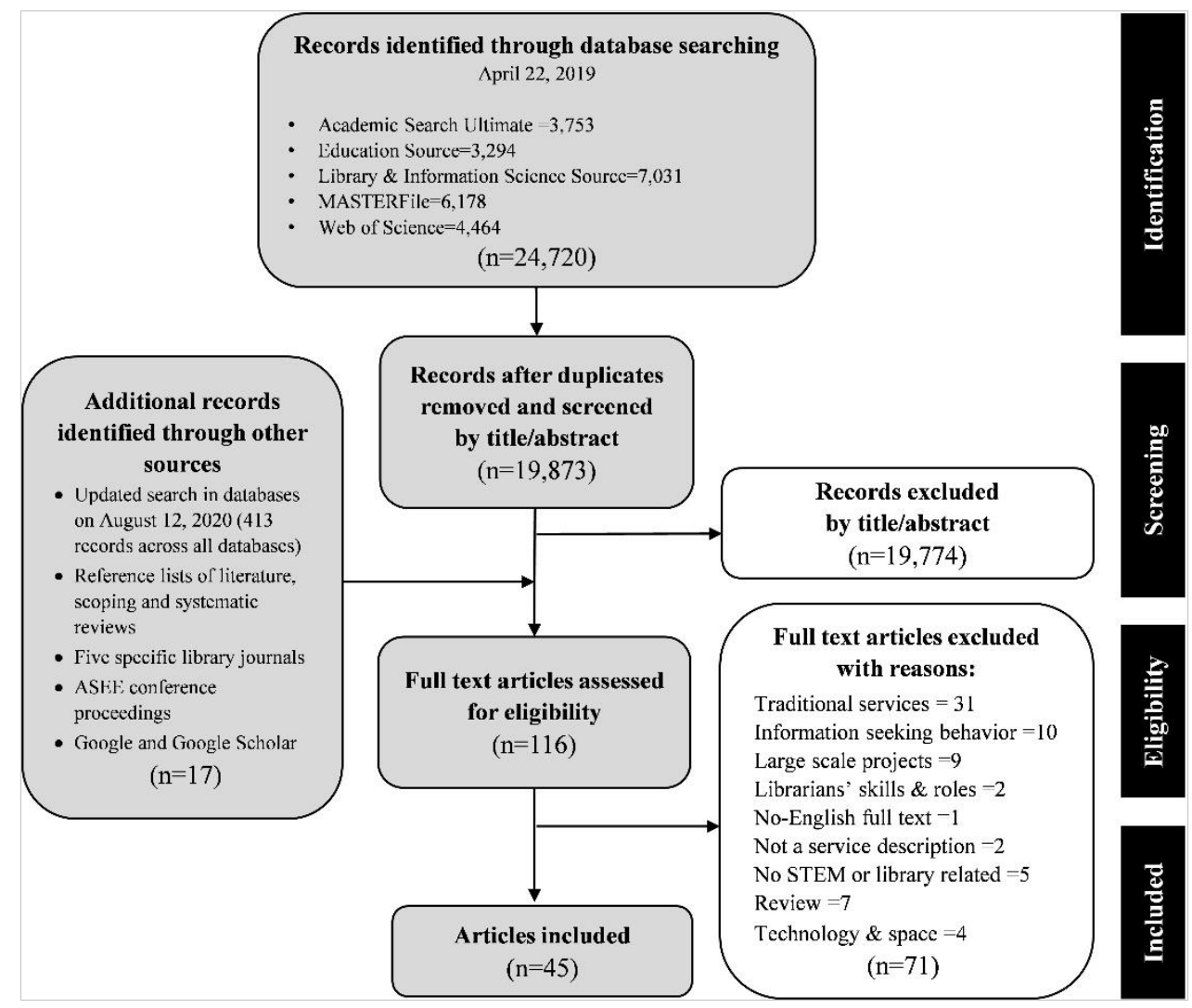

Figure 2. PRISMA flow diagram of search and study inclusion process

\section{Characteristics of Included Studies}

Key information and main outcomes were summarized from each of the included 45 articles (Appendix 7). Figure 3 shows the distribution of studies involving research support services by year for 1990-2020.

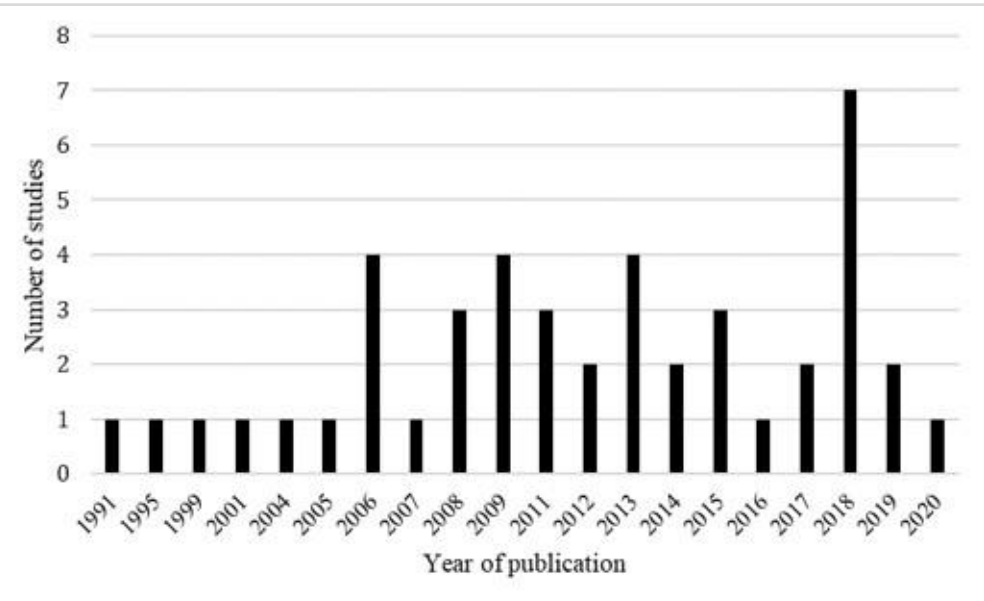

Figure 3. Number of included studies by year of publication

The most common non-traditional or specialized research support services described fall into the following areas: data management, geographic information systems, bibliometrics/altmetrics, patents, and systematic reviews (Figure 4). 


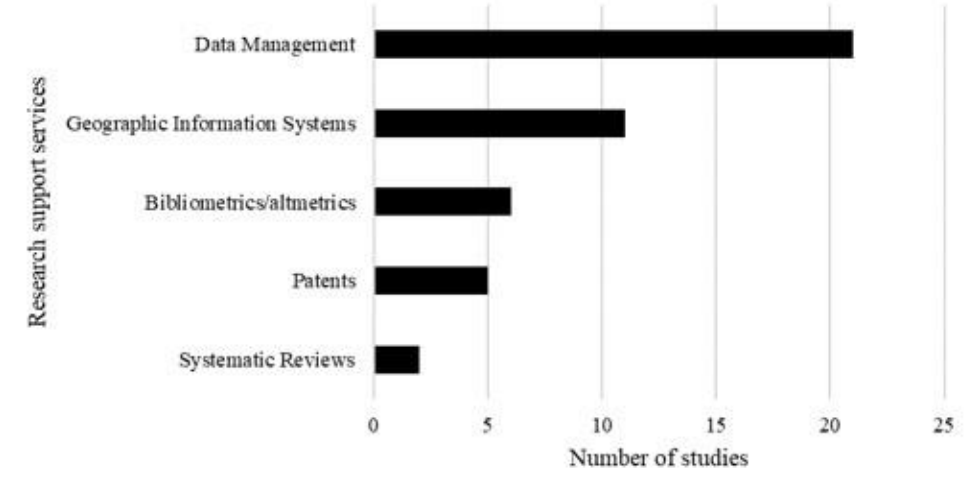

Figure 4. Number of included studies describing research support services

Figure 5 shows the publication venues for the 45 studies. The Journal of Academic Librarianship and Library Trends led the list with five articles each.

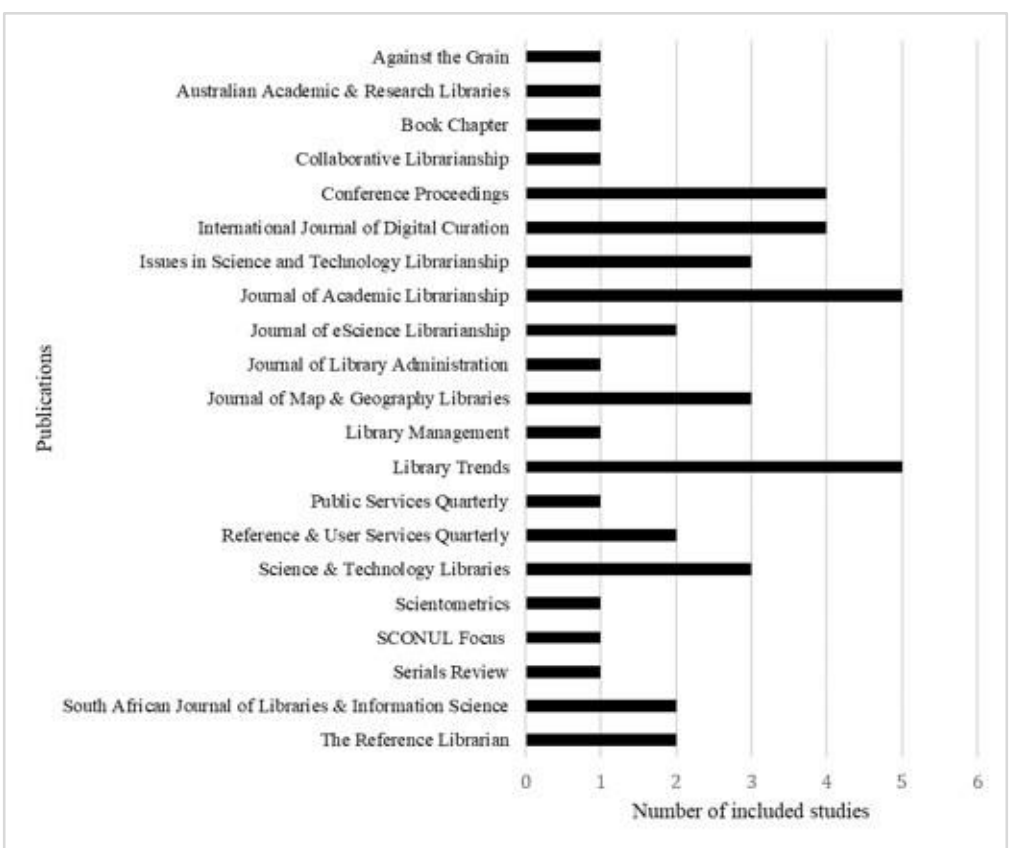

Figure 5. Number of included studies by publication

The number of non-traditional or specialized research support services are presented by country in Figure 6. The majority of the services described in the included studies were offered in the United States.

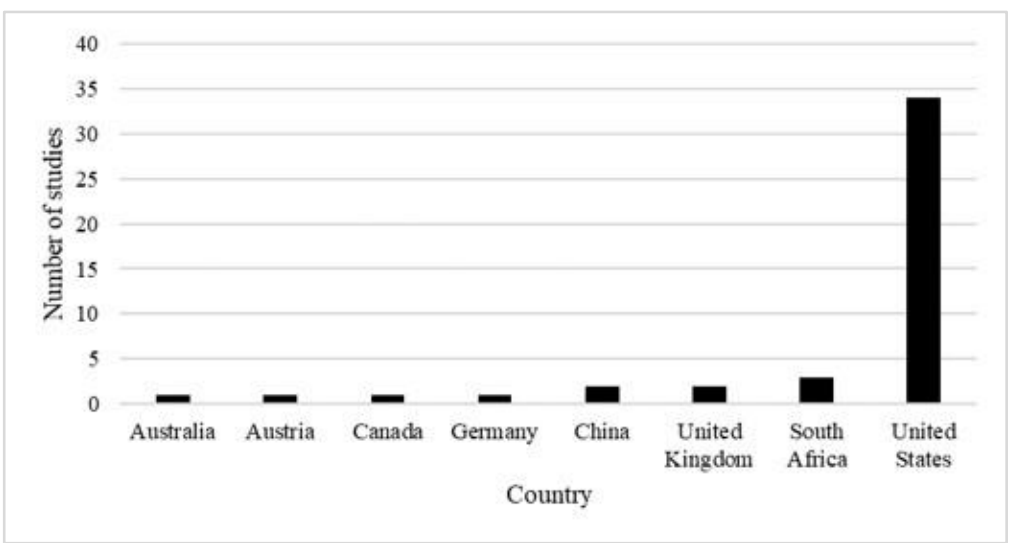

Figure 6. Research support services by country 


\section{Discussion}

The number of publications of non-traditional or specialized research support services increased after 2006 and remained steady over the years with a higher number being published in 2018 (Figure 3). The following synthesizes and discusses the studies included within the context of the five areas identified earlier in Figure 4: data management services, geographic information systems, bibliometrics and altmetrics, patents, and systematic reviews.

\section{Data Management Services ( $n=21$ )}

Approximately half of the 45 included articles in this scoping review described the development and implementation of data management services. Summaries of each article are included in Appendix 7. The 21 studies included in this scoping review trace the evolution of research data management services from 2006 to 2019 (Figure 7). Early articles emphasize data discovery and access to collections (Steinhart 2006; Read 2007). In 2008, the first discussion of institutional data repositories appeared, along with a discussion of data archiving and storage services (Choudhury 2008; Delserone 2008; Garritano \& Carlson 2009). Transitioning from traditional library services to offering more specialized research support requires assessing the users' needs (Peters \& Dryden 2011; Williams 2013) and acquiring new skills in data curation (Nelson 2011). Data management plans are more regularly discussed in the literature by 2013 along with an increased emphasis on user training by librarians (Choudhury 2013; Raboin et al. 2013; Shen \& Varvel 2013; Akers et al. 2014). More recent articles emphasize the importance of crossfunctional partnerships (Chiware \& Mathe 2015; Choudhury 2017), data visualization support (Ogier et al. 2018), and computational literacy (Oliver et al. 2019).

A major concern is the lack of librarians with the necessary skills to provide data management services (Akers et al. 2014) and academic institutions globally took various approaches in meeting this demand for specialized skills. In South Africa, the administration at the University of Pretoria took the lead to travel and learn from international experiences with research data management services (van Deventer \& Pienaar 2015).

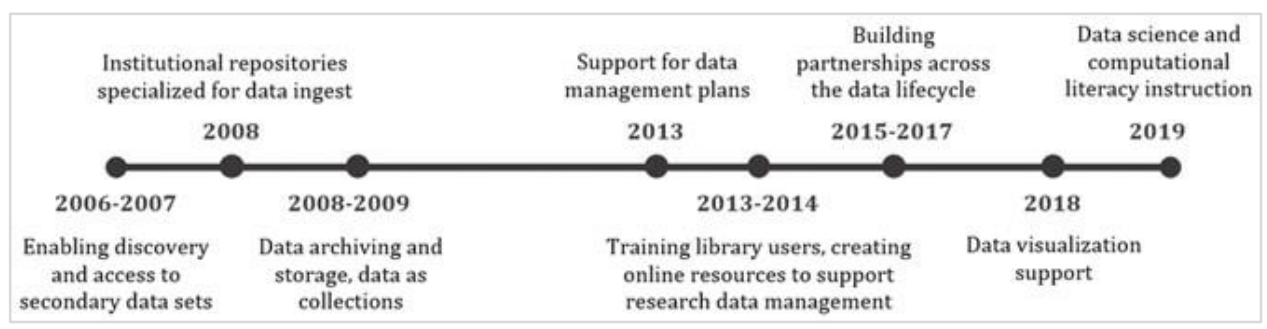

Figure 7. Timeline of data services described in the included studies

In the United States, the University of Minnesota hired a "science librarian cohort" to support interdisciplinary collaborations between researchers (Delserone 2008). The University of Arizona Libraries hired additional staff with specialized skills to lead workshops on computational literacy and open science (Oliver et al. 2019). Purdue University Libraries supported the Center for Authentic Science Practice in Education (CASPiE), an undergraduate research center funded by the National Science Foundation (Garritano \& Carlson 2009). Through this collaboration, they realized core skills for librarians that they already have and provided advice on how to further enhance these skills on the go. Virginia Tech Newman Library also took the collaborative approach and formed a team of disciplinary data and informatics consultants, enabling collaborations across disciplines and various units on campus (Griffin \& Lawlor 2019). A similar approach was used by three institutions - University of Wisconsin Madison, University of Massachusetts Amherst Libraries and Tufts University - that developed 
their research data management services after the National Science Foundation began requiring Data Management Plans in grant proposals (Raboin et al. 2013). Data visualization consultation is another aspect of the data management services that STEM libraries may offer (Ogier \& Stamper 2018).

In the United Kingdom, the University of Cambridge developed a "community of Data Champions," a peer-to-peer training program (Higman et al. 2017). Higman and colleagues (2017) described a creative, nonmonetary reward system to motivate participants in this "community of practice." Participants in this program include Ph.D. students, lecturers, data managers, librarians, or support staff equipped with skills to train their departmental colleagues in best practices of data management and sharing.

There are various approaches described in the included studies for the initial stages of research data management service development (Table 2). Several articles described services that filled previously unmet needs, so most evaluation activities were preliminary in nature and related to the establishment of new services. Study authors evaluated data management service success

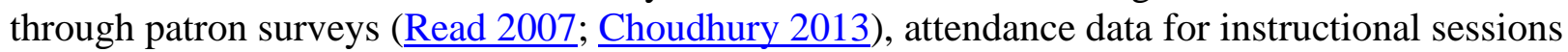
and consultations (Shen \& Varvel 2013; Higman et al. 2017), number of training sessions (Oliver et al. 2019) and the growth of data in institutional repositories (Choudhury 2017). To plan the data management services, researchers' data practices were evaluated in two studies (Walters 2009; Patterton et al. 2018). Lessons learned were described in two studies providing insights and challenges for creating a new service (Choudhury 2013; Ogier \& Stamper 2018).

Researchers also provided anecdotal evidence of the success of the data management services which resulted in more connections between librarians and faculty (Peters \& Dryden 2011), and practical recommendations for service development (Raboin et al. 2013). Other measures of success mentioned in the included studies were user satisfaction and increased awareness of the data management services (Steinhart 2006; Williams 2013; Chiware \& Mathe 2015), as well as identified potential collaborative projects between librarians and researchers (Delserone 2008; Garritano \& Carlson 2009; Nelson 2011).

Table 2. Activities at the beginning of the data management planning

\begin{tabular}{|c|c|}
\hline Activities & Studies \\
\hline $\begin{array}{l}\text { Surveys to assess the research needs of } \\
\text { their academic communities }\end{array}$ & $\begin{array}{l}\text { Read 2007; } \\
\text { et al. 2014; }\end{array} \underline{\text { Ogier et al. 2018 }}$; $\underline{\text { Patterton et al. } 2018}$ \\
\hline Interviews, dialogues, and consultations & $\begin{array}{l}\text { Choudhury 2008; Delserone 2008; Walters 2009; } \\
\text { Nelson 2011; Peters \& Dryden 2011; Shen \& } \\
\text { Varvel 2013; Choudhury 2013; Williams 2013; } \\
\underline{\text { Akers et al. } 2014 ; \text { van Deventer \& Pienaar 2015 }}\end{array}$ \\
\hline $\begin{array}{l}\text { Development of Research Data } \\
\text { Management policies }\end{array}$ & $\begin{array}{l}\text { Steinhart 2006; } \\
\text { van Deventer \& Pienaar 2015 }\end{array}$ \\
\hline $\begin{array}{l}\text { Building an infrastructure that is } \\
\text { embedded within researchers' workflow } \\
\text { and processes }\end{array}$ & Chiware \& Mathe 2015; Choudhury 2017 \\
\hline
\end{tabular}


There were eleven studies that provided insights into the development of GIS services at a STEM Library or a library serving researchers in STEM disciplines. Before embarking on the planning, developing and implementing a formal GIS service, March (2011) explored the researchers' needs, while Sweetkind-Singer and Williams (2001) visited other universities' GIS labs, and Kinikin and Hench (2005) surveyed academic libraries with GIS services to learn about existing practices and to provide a road map for authors to solicit administrative support. A similar approach was undertaken by Macfarlane and Rodgers (2008) who hired two interns from the Geography Department of the Middlebury College. The interns assessed the needs for GIS support on campus, promoted the GIS applications through print materials and electronic newsletter, and provided workshops and individual consultations to researchers. The University of Kansas responded to their users' research needs by increasing the subject expertise of their existing staff and acquiring the necessary technology and resources (Houser 2006). Building a dedicated lab space for course work and research, as well as offering a suite of specialized GIS workshops were some of the effective approaches taken by the universities (Sweetkind-Singer \& Williams 2001; Houser 2006). Allocating funding for the acquisitions of hardware and software proved to be crucial for launching a successful GIS service (Suh \& Lee 1999; Kinikin \& Hench 2005; March 2011).

Scaramozzino et al. (2014) described GIS service models at five academic libraries and provided "a rich collection of experiences, lessons learned, and [...] challenges from among the library GIS community from which program managers can learn as they continue to develop." Two studies described a three-level service and software use (Abbott \& Argentati 1995; Boissé \& Larsgaard 1995), while one study provided insights into providing GIS services in a single location in a library rather than in departmental labs (

Policy implementation is outlined in three studies (Abbott \& Argentati 1995; Suh \& Lee 1999; Scaramozzino et al. 2014). In addition to building the infrastructure for the provision of GIS services, it is equally important to recognize the amount of time librarians spend in research consultations. Through the analysis of the GIS consultation statistics, Parrish (2006) identified the types of patrons in order to conduct research consultations in an effective and efficient manner.

Success of GIS service implementation is measured quantitatively through the collection of statistics on the number of research consultations (Parrish 2006; March 2011; Scaramozzino et al. 2014), instruction sessions (Scaramozzino et al. 2014), workshop attendance (Houser 2006), and GIS lab use (Olson 2004). Using qualitative methods, authors evaluated their services by collecting feedback from their users (Olson 2004; Houser 2006). One study measured success through an increased number of GIS stations and the addition of a full-time and a part-time staff to meet GIS service demand (Kinikin \& Hench 2005), while two studies reported an increased awareness of GIS applications among students and researchers (Sweetkind-Singer \& Williams 2001; Macfarlane \& Rodgers 2008). Based on their experiences with the implementation of the new GIS service, several studies provided recommendations on meeting the users' needs (Abbott $\underline{\text { \& Argentati 1995; }}$ Suh \& Lee 1999), and on exploration of funding opportunities (Boissé \& Larsgaard 1995).

\section{Bibliometrics and Altmetrics $(n=6)$}

Bibliometrics and altmetrics services were another category of research support in academic libraries. The six studies described the development of the bibliometric or altmetric services to support research using a variety of approaches (Ball \& Tunger 2006; Drummond \& Wartho 
2009; Delasalle 2011; Gumpenberger et al. 2012; Nelson 2016; Abernethy \& Holderied 2018). Due to the increased number of requests for citation metrics, the United States Environmental Protection Agency in Research Triangle Park expanded their reference services to include Research Impact Reports and Article Impact Reports to address the demand (Abernethy \& Holderied 2018). Exploring new metrics such as altmetrics, as well as data visualization tools to create reports of high quality, allowed librarians to bring more value in their current service offerings (Nelson 2016; Abernethy \& Holderied 2018). A similar approach was undertaken by the University of New South Wales, where the library developed the Research Impact Measurement Service to support the university's strategic goals (Drummond \& Wartho 2009). Several case studies outlined the benefits from these transformed services, such as providing valuable information to researchers for grant applications, tenure, and promotion, and institutional comparison (Ball \& Tunger 2006; Drummond \& Wartho 2009; Delasalle 2011; Abernethy \& Holderied 2018).

While the previously described approaches led to enhancing an existing service and bringing value to the libraries, the University of Vienna established a separate Bibliometrics Department and formed an inter-institutional working group charged to coordinate all university units dealing with bibliometric activities (Gumpenberger et al. 2012). As a result, the department was engaged in different areas, such as teaching, consultations, organizing events, developing partnerships, participating in projects, and scientific output.

Two services were evaluated informally, based on customer input and counts of published reports (Drummond \& Wartho 2009; Abernethy \& Holderied 2018;), while other studies highlighted the benefit of positioning the library as a value-added service provider to the existing traditional services (Ball \& Tunger 2006; Delasalle 2011). One study demonstrated the success of the bibliometric research support service through the expansion of services to include outside organizations, hosting conferences and more (Gumpenberger et al. 2012). Altmetrics were discussed as a potential strategy for helping engineering faculty to identify interdisciplinary research collaborators and create an online social presence that raises faculty professional profiles and increases the impact of their research (Nelson 2016).

\section{Patents $(n=5)$}

Five articles that described a patent service in libraries serving STEM disciplines were identified (Thomas 1991; Zhang 2009; Feng \& Zhao 2015; Irvin 2018; Zhang \& Peng 2018).

With their educational roles, STEM librarians are well suited to incorporate patent searching in their instructional and reference efforts and highlight these underutilized resources of scientific contributions (Thomas 1991; Zhang 2009; Irvin 2018). The University of Saskatchewan developed a systematic patent training program based on the analysis of citation patterns of all the patents granted to the university (Zhang 2009). The team-based patent service offered at the Nanjing Technology University Library provided a detailed description of the planning, development, and implementation of this program (Feng \& Zhao 2015). Another service model is the four-tiered patents service that could be easily integrated into the regular reference service activities (Thomas 1991). Recognizing different types of users and their information needs offered professional development opportunities for early-career librarians to deepen their subject expertise in the patents field (Thomas 1991; Zhang \& Peng 2018).

Patent service evaluations differ across studies. Two studies measured success through users' appreciations and anecdotal evidence (Thomas 1991) and highlighted several benefits such as professional development opportunity for library staff and increased visibility of the library. In 
another study, a bibliometric analysis of an institution's patents was used to inform, enhance, and target a patent searching training program (Zhang 2009).

\section{Systematic Reviews ( $n=2)$}

STEM librarians are taking initial steps in developing systematic review services as more scientists and engineers are starting to use this methodology in their research activities. The team-based systematic review service at the University of Minnesota (Riegelman \& Kocher 2018), as well as the three-tiered model at the University of Maryland in College Park (Tchangalova et al. 2020), presented successful practices beyond the health and medical libraries. Both studies presented measures of success including statistics, feedback from researchers and anecdotal evidence.

\section{Limitations}

Limitations should be considered when interpreting the findings of this review. First, the included articles focused only on small and medium scale projects that would be beneficial to early-career librarians or those interested in new research support services to chart the areas where they initially could direct their efforts. Second, only full-text articles in English were included, thereby excluding research published in other languages due to the lack of reliable translation services. Third, although the literature search strategies were extensive, some studies may have been missed due to the following reasons: (1) the use of the Boolean operator NOT may have excluded STEM articles that also included health science or medical libraries; or (2) because the search terms have failed to identify these relevant studies. For example, in the search strategy the term "geography" was included, but not "geographic," "geographical," "GIS," and "Geospatial," and thus articles related to GIS programs and services may have been missed.

Since the scoping review only includes scholarly output, the analysis included here does not fully capture the scope of new research support services in academic and special libraries with a STEM focus. Many of these new services are featured on library web sites, discussed at conferences, or described in less formal publication venues. A greater emphasis on publishing in the searchable literature by all STEM librarians would provide both new and experienced librarians with a more complete understanding of the types of services that could be possible in their own libraries.

\section{Conclusion}

The studies examined in this scoping review frequently reported the establishment of services in data management and GIS. These are areas that offer many opportunities, along with associated challenges, for further development, especially with the emergence of new technology tools. Patent and bibliometrics/altmetrics services are not as frequently described in the literature, and future program descriptions and studies are welcomed to share successful practices, challenges, and opportunities. The small number of systematic review services identified in this review highlighted an opportunity for STEM librarians to share best practices in this direction. In today's information-saturated environment, librarians who learn the systematic review methodology and implement these services will be able to participate as valuable contributors to research projects with faculty in STEM disciplines.

This scoping review presents a systematic overview of the published literature on non-traditional or specialized research support services in academic and special libraries. It summarizes the literature on innovative services in the STEM libraries and offers inspirational ideas for enhancing existing services or developing new ones based on target audiences. This study will be 
beneficial to all STEM librarians, especially the ones at the beginning of their careers, who would like to bring more value to the services they offer, thus increasing the impact of their libraries.

\section{Acknowledgments}

The authors gratefully acknowledge the insightful comments made by Wichor Bramer (University Medical Center Rotterdam, Netherlands) and Stephanie Ritchie (University of Maryland STEM Library, US) on the key terms and the search strategy. We also would like to thank our colleagues at the University of Maryland Libraries - David Durden for setting up the REDCap survey and for providing feedback on the manuscript; Nevenka Zdravkovska and Sarah Over for testing the REDCap survey. We are very thankful for the constructive comments and recommendations provided by the reviewers and editors of the Issues in Science and Technology Librarianship.

\section{Funding}

This research was funded from the University of Maryland Libraries' Research Fund grant.

\section{Conflict of Interest}

The authors declare no conflict of interest. This material has not been presented before.

\section{Authors' Contributions}

All authors have made significant contributions to this scoping review. As a principal investigator, JC contributed to the scoping review protocol, developed the REDCap survey instrument, and secured the funds for the study. As a first author, NT collaborated in the protocol development, was involved in all review phases, as well as in the preparation of the manuscript draft. Reviewers with data visualization expertise (JC, NT, AT) collectively contributed to the development of keywords. At the time of the study, library graduate assistant (AP) added to the definitions used in this study. The scoping review team (JC, AP, NT, AT) collectively contributed to the critical revision of the manuscript and its final approval for the publication. All authors have read and approved the final version of this manuscript.

\section{Supporting Information}

Appendix 1: Preliminary Searches

Appendix 2: List of Databases with Results from the Preliminary Search in the Subject Field (DE) Appendix 3: Survey Instrument in REDCap

Appendix 4: STEM Related Listservs

Appendix 5: List of Search Terms

Appendix 6: Search Strategies

Appendix 7: Included Studies

Appendix 8: PRISMA-ScR Checklist

\section{References}

Abbott, L.T. \& Argentati, C.D. 1995. GIS: A new component of public services. The Journal of Academic Librarianship 21(4):251-256. DOI: 10.1016/0099-1333(95)90004-7.

Abernethy, T. \& Holderied, A. 2018. Implementing new bibliometric services at EPA-RTP Library. Serials Review 44(3):204-210. DOI: 10.1080/00987913.2018.1549695. 
Akers, K.G., Sferdean, F.C., Nicholls, N.H. \& Green, J.A. 2014. Building support for research data management: Biographies of eight research universities. International Journal of Digital Curation 9(2):171-191. DOI: 10.2218/ijdc.v9i2.327.

American Library Association. [date unknown]. Types of libraries [Internet]. [accessed 2020 Dec 10]. Available from http://www.ala.org/educationcareers/careers/librarycareerssite/typesoflibraries.

Antell, K., Foote, J.B., Turner, J. \& Shults, B. 2014. Dealing with data: Science librarians' participation in data management at Association of Research Libraries institutions. College \& Research Libraries 75(4):557-574. DOI: 10.5860/crl.75.4.557.

Arksey, H. \& O’Malley, L. 2005. Scoping studies: Towards a methodological framework. International Journal of Social Research Methodology 8(1):19-32.

DOI: $10.1080 / 1364557032000119616$.

Auckland, M. 2012. Re-skilling for research: An investigation into the role and skills of subject and liaison librarians required to effectively support the evolving information needs of researchers [Internet]. [accessed 2020 Dec 10]. Available from http://hdl.voced.edu.au/10707/204093.

Ball, R. \& Tunger, D. 2006. Bibliometric analysis - A new business area for information professionals in libraries? Scientometrics 66(3):561-577. DOI: 10.1007/s11192-006-0041-0.

Beck, D.M. \& Callison, R. 2006. Becoming a science librarian. Science \& Technology Libraries 27(1-2):71-98. DOI: 10.1300/J122v27n01_06.

Boissé, J.A. \& Larsgaard, M. 1995. GIS in academic libraries: A managerial perspective. The Journal of Academic Librarianship 21(4):288-291. DOI: 10.1016/0099-1333(95)90010-1.

Booth, A. 2006. Clear and present questions: Formulating questions for evidence based practice. Library Hi Tech 24(3):355-368. DOI: 10.1108/07378830610692127.

Borah, R., Brown, A.W., Capers, P.L. \& Kaiser, K.A. 2017. Analysis of the time and workers needed to conduct systematic reviews of medical interventions using data from the PROSPERO registry. BMJ Open 7(2):e012545. DOI: 10.1136/bmjopen-2016-012545.

Bramer, W.M., de Jonge, G.B., Rethlefsen, M.L., Mast, F. \& Kleijnen, J. 2018. A systematic approach to searching: An efficient and complete method to develop literature searches. Journal of the Medical Library Association 106(4):531-541. DOI: $10.5195 / \mathrm{jmla} .2018 .283$.

Bramer, W.M., Giustini, D. \& Kramer, B.M.R. 2016. Comparing the coverage, recall, and precision of searches for 120 systematic reviews in Embase, MEDLINE, and Google Scholar: A prospective study. Systematic Reviews 5:39. DOI: 10.1186/s13643-016-0215-7.

Bramer, W.M., Rethlefsen, M.L., Kleijnen, J. \& Franco, O.H. 2017. Optimal database combinations for literature searches in systematic reviews: A prospective exploratory study. Systematic Reviews 6:245. DOI: 10.1186/s13643-017-0644-y.

Chang, B., Carroll, A. \& Nickels, C. 2018. A study of research support service needs for civil, construction, and environmental engineering researchers at North Carolina State University [Internet]. [accessed 2020 Dec 10]. Available from http://www.lib.ncsu.edu/resolver/1840.20/35687. 
Chiware, E. \& Mathe, Z. 2015. Academic libraries' role in research data management services: A South African perspective. South African Journal of Libraries and Information Science 81(2):1-10. DOI: $10.7553 / 81-2-1563$.

Choudhury, G.S. 2008. Case study in data curation at Johns Hopkins University. Library Trends 57(2):211-220. DOI:10.1353/lib.0.0028.

Choudhury, G.S. 2013. Case study 1: Johns Hopkins University data management services. In: Pryor, G., Jones, S. \& Whytre, A., editors. Delivering Research Data Management Service: Fundamentals of Good Practice. London (UK): Facet Publishing. p. 115-133.

Choudhury, G.S. 2017. Data management and preservation of digital research data. Against the Grain 29(5):30-34. DOI: 10.7771/2380-176X.7838.

Coalter, J., Tchangalova, N. \& Trost, A. 2019. Using data visualization tools to design a search strategy for a systematic review. Poster presented at the UMD Libraries Research and Innovative Practice Forum. DOI: 10.13016/3fel-hsou.

Cooper, D., Springer, R., Benner, J.G., Bloom, D., Carrillo, E., Carroll, A., Chang, B., Chen, X., Daix, E., Dommermuth, E, et al. 2019. Supporting the changing research practices of civil and environmental engineering scholars. ITHAKA S+R. DOI: $\underline{10.18665 / \mathrm{sr} .310885}$.

Daudt, H.M., van Mossel, C. \& Scott, S.J. 2013. Enhancing the scoping study methodology: A large, inter-professional team's experience with Arksey and O'Malley's framework. BMC Medical Research Methodology 13:48. DOI: 10.1186/1471-2288-13-48.

Delasalle, J. 2011. Research evaluation: Bibliometrics and the librarian. SCONUL Focus. 53:1519. [accessed 2020 Dec 10]. Available from https://www.sconul.ac.uk/sites/default/files/documents/5 1.pdf.

Delserone, L.M. 2008. At the watershed: Preparing for research data management and stewardship at the University of Minnesota Libraries. Library Trends 57(2):202-210. DOI: 10.1353/lib.0.0032.

Dempsey, L. 2013. Three challenges: Engaging, rightscaling and innovating [Internet]. Lorcan Dempsey's Weblog. [accessed 2020 Dec 10]. Available from http://orweblog.oclc.org/threechallenges-engaging-rightscaling-and-innovating/.

Dohe, K., Hamidzadeh, B. \& Wallberg, B. 2019. Doing more, with more: Academic libraries, digital services, and revenue generation. [Issue Brief]. Ithaka S+R. DOI: 10.18665/sr.310917.

Drummond, R. \& Wartho, R. 2009. RIMS: The research impact measurement service at the University of New South Wales. Australian Academic \& Research Libraries 40(2):76-87. DOI: $\underline{10.1080 / 00048623.2009 .10721387 .}$

Falconer, J. 2015. Library support for systematic reviews at the London School of Hygiene \& Tropical Medicine. ALISS Quarterly 10(3):17-19. Available from https://researchonline.1shtm.ac.uk/id/eprint/2783036.

Feng, J. \& Zhao, N. 2015. A new role of Chinese academic librarians: The development of embedded patent information services at Nanjing Technology University Library, China. The Journal of Academic Librarianship 41(3):292-300. DOI: 10.1016/j.acalib.2015.03.010. 
Garritano, J. \& Carlson, J. 2009. A subject librarian's guide to collaborating on e-science projects. Issues in Science and Technology Librarianship 57. DOI: 10.5062/F42B8VZ3.

Goetsch, L.A. 2008. Reinventing our work: New and emerging roles for academic librarians. Journal of Library Administration 48(2):157-172. DOI: 10.1080/01930820802231351.

Gonzalez, H.B. \& Kuenzi, J.J. 2012. Science, technology, engineering, and mathematics (STEM) education: A primer [Internet]. Washington (DC): Congressional Research Service. [accessed 2020 Dec 10]. Available from https://fas.org/sgp/crs/misc/R42642.pdf.

Griffin, J. \& Lawlor, B. 2019. Leadership to advance data and information science at Virginia Tech library. Information Services \& Use 39(3):177-181. DOI:10.3233/ISU-190042.

Gumpenberger, C., Wieland, M. \& Gorraiz, J. 2012. Bibliometric practices and activities at the University of Vienna. Library Management 33(3):174-183. DOI:

$\underline{110.1108 / 01435121211217199 .}$

Hackenberg, J.M. 2000. Who chooses sci-tech librarianship? College \& Research Libraries 61(5):441-450. DOI: 10.5860/crl.61.5.441.

Hardi, A.C. \& Fowler, S.A. 2014. Evidence-based medicine and systematic review services at Becker Medical Library. Missouri Medicine 111(5): 416-418. Available from https://www.ncbi.nlm.nih.gov/pmc/articles/PMC6172095/pdf/ms111_p0416.pdf.

Harris, P.A., Taylor, R., Minor, B.L., Elliott, V., Fernandez, M., O’Neal, L., McLeod, L., Delacqua, G., Delacqua, F., Kirby, J., et al. 2019. The REDCap consortium: Building an international community of software platform partners. Journal of Biomedical Informatics 95:103208. DOI: $\underline{10.1016 / j . j b i .2019 .103208 .}$

Harris, P.A., Taylor, R., Thielke, R., Payne, J., Gonzalez, N. \& Conde, J.G. 2009. Research electronic data capture (REDCap): A metadata-driven methodology and workflow process for providing translational research informatics support. Journal of Biomedical Informatics 42(2):377-381. DOI: $10.1016 /$ j.jbi.2008.08.010.

Higman, R., Teperek, M. \& Kingsley, D. 2017. Creating a community of data champions. International Journal of Digital Curation 12(2):96-106. DOI: $10.2218 / \mathrm{ijdc} . v 12 \mathrm{i} 2.562$.

Houser, R. 2006. Building a library GIS service from the ground up. Library Trends 55(2):315326. DOI: $10.1353 /$ lib.2006.0058.

Hubbard, D.E. 2017. Chemical lecture demonstrations: An opportunity for engagement through collections, instruction, and reference. Science \& Technology Libraries 36(4):376-389. DOI: 10.1080/0194262X.2017.1389667.

Hunter, C., Lake, S., Lee, C. \& Sallans, A. 2010. A case study in the evolution of digital services for science and engineering libraries. Journal of Library Administration 50(4):335-347. DOI: $\underline{10.1080 / 01930821003667005}$.

Irvin, D. 2018. The patent office in the library. Public Services Quarterly 14(4):392-398. DOI: $\underline{10.1080 / 15228959.2018 .1487360 .}$.

Jaguszewski, J. \& Williams, K. 2013. New roles for new times: Transforming liaison roles in research libraries [Report]. Washington (DC): Association of Research Libraries. [accessed 2020 Dec 10]. Available from http://hdl.handle.net/11299/169867. 
Johnson, V. 2017. Leveraging technical library expertise for big data management. Journal of the Australian Library and Information Association 66(3):271-286. DOI:

10.1080/24750158.2017.1356982.

Kinikin, J.N. \& Hench, K. 2005. Survey of GIS implementation and use within smaller academic libraries. Issues in Science and Technology Librarianship 42. DOI:

$\underline{10.5062 / \mathrm{F} 4 \mathrm{SX} 6 \mathrm{~B} 56 .}$.

Knehans, A., Dell, E. \& Robinson, C. 2016. Starting a fee-based systematic review service. Medical Reference Services Quarterly 35(3):266-273. DOI:

$\underline{10.1080 / 02763869.2016 .1189779 .}$.

Kung, J.Y.C. \& Chambers, T. 2019. Implementation of a fee-based service model to university-affiliated researchers at the University of Alberta. Journal of the Medical Library Association 107(2):238-243. DOI: 10.5195/jmla.2019.497.

Ludeman, E., Downton, K., Shipper, A.G. \& Fu, Y. 2015. Developing a library systematic review service: A case study. Medical Reference Services Quarterly 34(2):173-180. DOI: $\underline{10.1080 / 02763869.2015 .1019323 .}$.

MacDonald, K.I. 2018. The business of chemistry: Opportunities for interdisciplinary collaboration in information literacy. Science \& Technology Libraries 37(4):323-331. DOI: $\underline{10.1080 / 0194262 X .2018 .1515689 .}$.

Macfarlane, C.M. \& Rodgers, C.M. 2008. Geospatial technology support in small academic libraries: Time to jump on board? Issues in Science and Technology Librarianship 55. DOI: 10.5062/F4GF0RFV.

Mann, M. \& Weightman, A. 2013. Support unit for research evidence: Supporting staff and students conducting systematic reviews. ALISS Quarterly 8(3):13-15.

March, G.H. 2011. Surveying campus GIS and GPS users to determine role and level of library services. Journal of Map \& Geography Libraries 7(2):154-183. DOI:

$\underline{10.1080 / 15420353.2011 .566838 .}$.

McGowan, J., Sampson, M., Salzwedel, D.M., Cogo, E., Foerster, V. \& Lefebvre, C. 2016. PRESS peer review of electronic search strategies: 2015 guideline statement. Journal of Clinical Epidemiology 75:40-46. DOI: 10.1016/j.jclinepi.2016.01.021.

Nelson, M.R.S. 2016. Using altmetrics as an engineering faculty outreach tool. Paper presented at the 2016 American Society for Engineering Education Annual Conference \& Exposition; 2016 Jun 26-29; New Orleans, LA. Washington (DC): American Society for Engineering Education. DOI: $\underline{10.18260 / p .27127 .}$.

Nelson, M.S. 2011. Connecting with data: First steps toward an emerging area of library service. Paper presented at the 2011 American Society for Engineering Education Annual Conference \& Exposition; 2011 Jun 26-29; Vancouver, Canada. Washington (DC): American Society for Engineering Education. DOI: 10.18260/1-2--17656.

Ogier, A., Brown, A., Petters, J., Hilal, A. \& Porter, N. 2018. Enhancing collaboration across the research ecosystem: Using libraries as hubs for discipline-specific data experts. Proceedings of the Practice and Experience on Advanced Research Computing (PEARC '18); 2018 Jul 22- 
26; Pittsburgh. PA. New York (NY): Association for Computing Machinery. DOI: $\underline{10.1145 / 3219104.3219126 .}$.

Ogier, A. \& Stamper, M.J. 2018. Data visualization as a library service: Embedding visualization services in the library research lifecycle. Journal of eScience Librarianship 7(1):e1126. DOI: 10.7191/jeslib.2018.1126.

Ogungbeni, J.I., Obiamalu, A.R., Ssemambo, S. \& Bazibu, C.M. 2018. The roles of academic libraries in propagating open science: A qualitative literature review. Information Development 34(2):113-121. DOI: $10.1177 / 0266666916678444$.

Oliver, J.C., Kollen, C., Hickson, B. \& Rios, F. 2019. Data science support at the academic library. Journal of Library Administration 59(3):241-257. DOI: 10.1080/01930826.2019.1583015.

Olson, J.A. 2004. Library-based GIS labs. Journal of Map \& Geography Libraries 1(1):75-88. DOI: $\underline{10.1300 / J 230 v 01 \mathrm{n} 01 \_05 .}$.

Parrish, A. 2006. Improving GIS consultations: A case study at Yale University Library. Library Trends 55(2):327-339. DOI: 10.1353/lib.2006.0060.

Patterton, L., Bothma, T.J.D. \& van Deventer, M.J. 2018. From planning to practice: An action plan for the implementation of research data management services in resource-constrained institutions. South African Journal of Libraries and Information Science 84(2):14-16. DOI: 10.7553/84-2-1761.

Peters, C. \& Dryden, A.R. 2011. Assessing the academic library's role in campus-wide research data management: A first step at the University of Houston. Science \& Technology Libraries 30(4):387-403. DOI: 10.1080/0194262X.2011.626340.

Raboin, R., Reznik-Zellen, R.C. \& Salo, D. 2013. Forging new service paths: Institutional approaches to providing research data management services. Journal of eScience Librarianship 1(3):134-147. DOI: 10.7191/jeslib.2012.1021.

Read, E.J. 2007. Data services in academic libraries. Reference \& User Services Quarterly 46(3):61-75. DOI: 10.5860/rusq.46n3.61.

Riegelman, A. \& Kocher, M. 2018. A model for developing and implementing a systematic review service for disciplines outside of the health sciences. Reference \& User Services Quarterly 58(1):22-27. DOI: 10.5860/rusq.58.1.6837.

Roth, S.C. 2018. Transforming the systematic review service: A team-based model to support the educational needs of researchers Journal of the Medical Library Association 106(4):514-520. DOI: $10.5195 / \mathrm{jmla} .2018 .430$.

Salisbury, L. \& Mattice, G. 2016. Early exposure to the scientific research process through collaboration with chemistry faculty and the science librarian. Science \& Technology Libraries 35(2):119-135. DOI: 10.1080/0194262X.2016.1162118.

Scaramozzino, J., White, R., Essic, J., Fullington, L.A., Mistry, H., Henley, A. \& Olivares, M. 2014. Map room to data and GIS services: Five university libraries evolving to meet campus needs and changing technologies. Journal of Map \& Geography Libraries 10(1):6-47. DOI: $\underline{10.1080 / 15420353.2014 .893943 .}$. 
Shen, Y. \& Varvel, V.E. 2013. Developing data management services at the Johns Hopkins University. Journal of Academic Librarianship 39(6):552-557. DOI:

10.1016/j.acalib.2013.06.002.

Smith, R. \& Bridle, O. 2018. Using virtual reality to create real world collaborations.

Proceedings of the 39th IATUL Conference; 2018 Jun 17-21; Oslo, Norway. Available from https://docs.lib.purdue.edu/iatul/2018/collaboration/5.

Steinhart, G. 2006. Libraries as distributors of geospatial data: Data management policies as tools for managing partnerships. Library Trends 55(2):264-284. DOI:. 10.1353/lib.2006.0063.

Suh, H-S.J. \& Lee, A. 1999. Embracing GIS services in libraries: The Washington State University experience. The Reference Librarian 30(64):125-137. DOI: 10.1300/J120v30n64_10.

Sweetkind-Singer, J. \& Williams, M. 2001. Supporting the information needs of geographic information systems (GIS) users in an academic library. Science \& Technology Libraries 21(34):175-190. DOI:.10.1300/J122v21n03_11.

Tchangalova, N. 2009. Jumping onto the bandwagon: New librarians navigating the science/technology librarianship. Electronic Journal of Academic and Special Librarianship 10(3). Available from http://southernlibrarianship.icaap.org/content/v10n03/tchangalova_n01.html.

Tchangalova, N., Harrington, E.G., Ritchie, S., Over, S. \& Coalter, J. 2020. Working across disciplines and library units to develop a suite of systematic review services for researchers. Collaborative Librarianship 11(4):6. Available from https://digitalcommons.du.edu/collaborativelibrarianship/vol11/iss4/6/.

Thomas, D.R. 1991. Out of the fire and into the frying pan: Hope for patent reference service in a non-patent depository library. The Reference Librarian 14(32):125-138. DOI:

10.1300/J120v14n32_09.

Tricco, A.C., Lillie, E., Zarin, W., O’Brien, K. K., Colquhoun, H., Levac, D., Moher, D., Peters, M.D.J., Horsley, T., Weeks, L., et al. 2018. PRISMA extension for scoping reviews (PRISMA-ScR): Checklist and explanation. DOI: 10.7326/M18-0850. Annals of Internal Medicine 169(7):467-473. DOI: 10.7326/M18-0850.

U.S. Immigration and Customs Enforcement. 2016. STEM designated degree program list [Internet]. Available from https://www.ice.gov/sites/default/files/documents/Document/2016/stem-list.pdf.

van Deventer, M. \& Pienaar, H. 2015. Research data management in a developing country: A personal journey. International Journal of Digital Curation 10(2):33-47. DOI: 10.2218/ijdc.v10i2.380.

Walter, S. 2011. "Distinctive signifiers of excellence": Library services and the future of the academic library. College \& Research Libraries 72(1):6-8. DOI: 10.5860/0720006.

Walters, T.O. 2009. Data curation program development in U.S. universities: The Georgia Institute of Technology example. International Journal of Digital Curation 4(3):83-92. DOI: $\underline{10.2218 / \mathrm{ijdc} . \mathrm{v} 4 \mathrm{i} 3.116 .}$ 
Williams, S.C. 2013. Using a bibliographic study to identify faculty candidates for data services. Science \& Technology Libraries 32(2):202-209. DOI: 10.1080/0194262X.2013.774622.

Zhang, C. \& Peng, L. 2018. Patent information service issues and countermeasures for college libraries: Taking Huazhong University of Science and Technology as an example. International Conference on Education Science and Economic Management (ICESEM 2018); 2018 Aug 2526; Xiamen, China. Amsterdam: Atlantic Press. 895-898. DOI: 10.2991/icesem-18.2018.209.

Zhang, L. 2009. Developing a systematic patent search training program. The Journal of Academic Librarianship 35(3):260-266. DOI: 10.1016/j.acalib.2009.03.010.

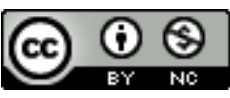

This work is licensed under a $\underline{\text { Creative Commons Attribution 4.0 International License }}$ 